\title{
ANNOTATIONS
}

\section{The Ophthalmologists and the General Medical Council}

In a short annotation we referred to this subject in our last issue, and we make no apology for discussing it again. The more the decision of the Council is examined, the more unsatisfactory does it seem. The impression is unavoidable that the Council has entirely misunderstood the situation, and especially its importance. The "light and airy" manner with which the subject was dealt with would imply that the Council regarded the recommendations of the ophthalmologists as an attempt to enforce their convictions by an act of fussy and inexcusable officiousness. Nothing, however, was further from this purpose. The recommendations were based upon an explicit realization of the disability to which the public were exposed by the scanty teaching of ophthalmology at the present day. This neglect, the Council was informed, could only be avoided by the introduction of a statutory examinational test, conducted of necessity by ophthalmic surgeons. Having regard to the importance of the issue, so far as the public were concerned, the reform suggested was rational and only in accord with a progressive line of policy which the times demand. Despite this, however, the Council has decided to assume a non possumus attitude. Furthermore, it is regrettable that the reasons upon which the decision was based were held from the ophthalmologists. There was surely due to the ophthalmologists a considered explanation of the grounds upon which their important recommendations were rejected; as there is no eye specialist amongst their number, courtesy alone demanded this, even from so august a body as the General Medical Council. The recommendations may have been deemed by the Council to be beyond its power to enforce, without a special clause to this effect in the Medical Acts. If that were so, why has the fact not been openly stated ? The Council has affirmed that its chief reason for pursuing a strenuous policy to improve and strengthen the Dental Acts, was the vigorous movement which was being taken in this direction by the dental profession in allied countries. It may be pointed out that the same policy of progress is being carried out in regard to ophthalmology, as a perusal of the medical journals, for example of America, will show ; that fact in itself emphasizes the importance of the recommendations of the Council of the British Ophthalmologists which the Medical Educational Authority of this country has declined to accept. This subject is discussed in a leading article in the Medical Press, July 2, in which the conclusion is arrived at that "impartial critics can scarcely admit that the position assumed by the General Medical Council redounds to the Council's credit. Modern times demand, not parochial restrictions, but advancement in matters educational." And to this 
we may add that where the issues to the public are so important as are those which the ophthalmologists have rightly claimed them to be, it is the duty of the Council to concede the introduction of a reform for which such urgent necessity has been shown.

\section{The Early Treatment of Ophthalmia Neonatorum}

In our last issue we noted that a practitioner was fined for failing to notify a case of ophthalmia neonatorum. The object of notification is not to prevent the spread of the disease, but to see that the child receives prompt and proper curative treatment, which as a rule cannot be carried out in the patient's own home.

In London, and in several of the larger towns, following the example of Manchester, special hospital accommodation is provided which will receive both mother and baby for treatment. In the metropolis, under the auspices of the Metropolitan Asylums Board, St. Margaret's Hospital, Leighton Road, Kentish Town, was opened last September, and it is proposed at a later date to open another hospital on the south side of the river. Ambulances are provided to remove both mother and baby to the hospital immediately on receipt of a message either by tèlephone or other means of communication with the Metropolitan Asylums Board.

For these hospitals to serve the purpose for which they are intended, namely, the prevention of blindness by corneal ulceration, which usually starts during the first few days of the disease, it is obvious that the cases must be admitted at the earliest possible moment. We are informed that during the first few months in which St. Margaret's Hospital was opened, the average date of admission was three weeks, which is obviously too late to prevent corneal ulceration. Latterly, the conditions have improved, partly on account of the more active representation of the Medical Officers of Health, and partly owing to the fact that the cases are now admitted on the request of the Midwives of the London County Council without losing time in obtaining a certificate from a Medical Officer. In spite of this there are still a number of children admitted to this hospital with severe corneal ulceration in a late stage of the disease. Many of these come from hospitals and general practitioners, both of which, although they have been informed of the existence of special hospitals, have forgotten their existence until too late to save the eyesight of the child. We cannot urge too strongly the necessity of the efficient and early treatment of the disease, and that practitioners and resident medical officers should from time to time be reminded of the existence of special hospitals for its treatment. 